\title{
Meat Quality Traits of Longissimus dorsi Muscle from Carcasses of Hanwoo Steers at Different Yield Grades
}

\author{
Samooel Jung, Ki Chang Nam¹, Kyung Haeng Lee², Jong Joo Kim³, and Cheorun Jo* \\ Department of Animal Science and Biotechnology, Chungnam National University, Daejeon 305-764, Korea \\ ${ }^{1}$ Department of Animal Science and Technology, Sunchon National University, Suncheon 540-742, Korea \\ ${ }^{2}$ Department of Food and Nutrition, Korea National University of Transportation, Jeungpyung 368-701, Korea \\ ${ }^{3}$ School of Biotechnology, Yeungnam University, Kyungsan 712-749, Korea
}

\begin{abstract}
The strategy for increasing the palatability of Hanwoo beef through fattening could lead to a decline in yield grade. The aim of this study was to examine the meat quality traits of Longissimus dorsi (LD) muscle from carcasses of Hanwoo steers at different yield grades. A total of 246 Hanwoo steers was divided into the following yield grades: A ( $\mathrm{n}=77), \mathrm{B}(\mathrm{n}=76)$ and $\mathrm{C}(\mathrm{n}=93)$. Meat quality traits, including proximate composition, cholesterol content, nucleotide content, dipeptide content, creatine and creatinine, free amino acid content, fatty acid composition, instrumental meat color, $\mathrm{pH}$, water holding capacity, drip loss, cooking loss, and sensory qualities of the LD muscle from the 3 yield grades of Hanwoo carcasses were measured. The decline in yield grade from $\mathrm{A}$ to $\mathrm{C}$ resulted in an increase in crude fat and cholesterol content as well as a decrease in inosine 5'-monophosphate and aspartic acid in the LD muscle $(p<0.05)$. In terms of fatty acid composition, the LD muscle from yield grade A had higher SFA and PUFA and lower MUFA content than that from yield grade $\mathrm{C}(p<0.05)$. However, the ratio of PUFA/SFA and n-6/n-3 did not differ among LD muscles from the 3 yield grades. There were no significant differences among other meat quality traits in relation to the yield grade. In conclusion, we suggest that the changes of substances related with health and flavor can be considered in order to obtain better quality Hanwoo beef.
\end{abstract}

Key words: beef yield grade, Hanwoo steers, meat quality

\section{Introduction}

The beef grading system for cattle carcasses reveals 2 types of information: quality grade and yield grade. The principal components for determining the quality or yield grade differ somewhat by country (Polkinghorne and Thompson, 2010). The high-quality grade in the beef grading system refers to high palatability of beef in many countries, including South Korea, Australia, Canada, Japan, and the USA, but signifies high yield of lean meat in Europe and South Africa (Polkinghorne and Thompson, 2010). High palatability of beef (i.e., more tender, juicy, and flavor-intensive) can be achieved by increasing marbling (Dashdorj et al., 2012; Jeremiah et al., 2003; Kim and Lee, 2003). Therefore, marbling score is a very important factor in determining the quality grade of beef in

*Corresponding author: Cheorun Jo, Department of Animal Science and Biotechnology, Chungnam National University, Daejeon 305-764, Korea. Tel: 82-42-821-5774, Fax: 82-42-825-9754, E-mail: cheorun@cnu.ac.kr the grading system. Many consumers who buy beef in retail stores expect high palatability and are willing to pay high prices for beef with a high quality grade (Jo et al., 2012).

Because of this trend, farmers of feedlot cattle commit to increasing marbling in cattle, which go through a fattening period during which they are fed concentrated feedstuffs before slaughter. Okumura et al. (2007) found that increasing the fattening period for Japanese Black steers from 24 to 30 mon resulted in an increase in carcass weight and intramuscular fat content of principal muscles. An increase in marbling score and the percentage of cattle graded "US Choice" was also reported by Van Koevering et al. (1995), who increased the feeding period of British and Continental crossbred yearling steers. However, this author found that an increase in the feeding period decreased feeding efficiency (carcass weight/feed intake). In addition, some researchers found no effect of increased fattening period of cattle on the marbling score and quality of beef (Iwamoto et al., 2009; Sami et al., 2004). 
High-palatability beef is preferred by consumers in Korea. In particular, Hanwoo beef, a native Korean cattle breed, was highly preferred over beef from imported breeds because of its freshness and high quality, despite its high price (Jo et al., 2012). Hanwoo cattle generally are fed a high level of concentrated diet during the fattening period, to increase intramuscular fat (Jo et al., 2012). However, this feeding system resulted in a decline of yield grade, which could cause a reduction in income for farmers (Lee et al., 2011). Fat deposition in cattle tissue by intense fattening appeared predominantly in the subcutaneous tissue rather than in the muscle tissue (Harper and Pethick, 2004). Therefore, intense fattening of cattle, especially during the final growth stage, leads to increased thickness of back fat, which contributes greatly to a decline in yield grade (Lee et al., 2011; Moon et al., 2003). A previous study reported that the thickness of back fat had a highly negative correlation (-0.85) with yield grade, and a low positive correlation ( 0.15$)$ with quality grade in Hanwoo steers (Lee et al., 2011).

From previous studies, we have learned that intense fattening of Hanwoo cattle mainly affected yield grade rather than quality grade of carcasses. However, studies of changes in yield grade and consequent differences in meat quality have not been performed. Therefore, the objective of this study was to examine the meat quality traits of Longissimus dorsi muscle from carcasses of Hanwoo steers at different yield grades.

\section{Materials and Methods}

\section{Animals and sample preparation}

Two-hundred and fifty Korean native cattle (Hanwoo steers, 27-30 mon old) were randomly selected from a group raised in NongHyup (Anseong). These cattle were slaughtered without electrical stimulation and cooled at $0^{\circ} \mathrm{C}$ for $24 \mathrm{~h}$ in a chilling room. Carcass weight ranged from 213 to $477 \mathrm{~kg}$ (average, $409 \mathrm{~kg}$ ). The cold carcasses were graded at $24 \mathrm{~h}$ postmortem with the loin surface ribbed between the $13^{\text {th }}$ rib and the $1^{\text {st }}$ lumbar vertebrae according to the Korean carcass grading procedure (National Livestock Cooperatives Federation, 1998). In the Korean beef grading system, the yield index is obtained from 3 variables: carcass weight $(\mathrm{kg})$, ribeye area $\left(\mathrm{cm}^{2}\right)$, and back fat thickness (mm). Each variable has a correction factor as follows: 0.625 for back fat thickness, 0.130 for ribeye area, and 0.024 for carcass weight. In the case of Hanwoo carcasses, a compensating factor of 3.23 is added to the function for yield index (notification from
MIFAFF, 2011-175).

Yield index $=68.184-[0.625 \times$ back fat thickness $(\mathrm{mm})]$

$+\left[0.130 \times\right.$ ribeye area $\left.\left(\mathrm{cm}^{2}\right)\right]$

$-[0.024 \times$ carcass weight $(\mathrm{kg})]+3.23$

Yield grade was scored by criteria revised as of January 2013
A grade (yield index $\geq 67.20$ )
B grade $(67.20<$ yield index $\geq 63.30)$
$\mathrm{C}$ grade (yield index $<63.30$ )

Of the 250 Hanwoo steers, 4 had a yield grade that was a step up or down in the grader's opinion, and were eliminated from the sample set for this study. The Longissimus dorsi (LD) muscles at the $14^{\text {th }}-18^{\text {th }}$ vertebrae were removed and transferred to the laboratory. After aging for $7 \mathrm{~d}$ at $4^{\circ} \mathrm{C}$, the subcutaneous and intermuscular fat and visible connective tissues of LD muscles were trimmed and used to analyze meat composition and quality parameters.

\section{Proximate composition}

The proximate composition of the LD muscles was determined by a slight modification of the AOAC (1995) method. Moisture content was obtained by drying $3 \mathrm{~g}$ of samples placed in aluminum dishes for $15 \mathrm{~h}$ at $104^{\circ} \mathrm{C}$. Crude protein content was measured by the Kjeldahl method (VAPO45, Gerhardt Ltd., Germany). The amount of nitrogen obtained was multiplied by 6.25 to calculate crude protein contents. Crude fat contents were measured by the Soxhlet extraction system (TT 12/A, Gerhardt Ltd., Germany). Crude ash content was measured by burning $2 \mathrm{~g}$ of samples overnight in a furnace at $600^{\circ} \mathrm{C}$.

\section{Nucleotides}

The meat samples $(5 \mathrm{~g})$ were mixed with $25 \mathrm{~mL}$ of 0.7 $\mathrm{M}$ perchloric acid and homogenized (T25b, Ika Works (Asia)., Sdn, Bhd, Malaysia) for $1 \mathrm{~min}$ at $1,130 \mathrm{~g}$ to extract nucleic acids. The extracted nucleic acids were centrifuged (Union 32R, Hanil Co., Ltd., Korea) for $15 \mathrm{~min}$ at 2,090 $\mathrm{g}\left(4^{\circ} \mathrm{C}\right)$ and filtered through Whatman No. 4 filter paper (Whatman Inc., England). The supernatant was then adjusted to $\mathrm{pH} 7$ with $5 \mathrm{~N} \mathrm{KOH}$ (SevenEasy, MettlerToledo Int. Inc., Switzerland). The $\mathrm{pH}$-adjusted supernatant was placed in a volumetric flask and adjusted to a volume of $100 \mathrm{~mL}$ with $0.7 \mathrm{M}$ perchloric acid (pH 7). After $30 \mathrm{~min}$ of cooling, the mixture was centrifuged (Union $32 \mathrm{R})$ at $2,090 \mathrm{~g}\left(4^{\circ} \mathrm{C}\right)$ and the supernatant was filtered through a $0.2-\mu \mathrm{m}$ PVDF syringe filter (Whatman). The 
filtrate $(5 \mathrm{~mL})$ was analyzed using HPLC (ACME 9000, Younglin Instruments Inc., Korea). The analytical conditions for HPLC included a Waters-Atlantis dC18 RP column (4.6×250 mm, $5 \mu \mathrm{m}$ particles, Waters Co., USA), with a mobile phase of $0.1 \mathrm{M}$ triethylamine in $0.15 \mathrm{M}$ acetonitrile $(\mathrm{pH} 7.0)$. The flow rate of the mobile phase was $1.0 \mathrm{~mL} / \mathrm{min}$, and the injection volume was $10 \mu \mathrm{L}$. The column temperature was maintained at $35^{\circ} \mathrm{C}$ and detection was monitored at a wavelength of $260 \mathrm{~nm}$. The peaks of individual nucleotides were identified using retention times for the following standards: hypoxanthine, inosine, inosine-5-phosphate (IMP), adenosine-5-phosphate (AMP) (Sigma, USA); the concentrations were calculated using the area for each peak.

\section{Carnosine, anserine, creatine, and creatinine}

Carnosine, anserine, creatine, and creatinine were determined by the method of Mora et al. (2007). Minced meat samples $(2.5 \mathrm{~g})$ were homogenized with $7.5 \mathrm{~mL}$ of $0.01 \mathrm{~N}$ $\mathrm{HCl}$ at 13,500 rpm for $1 \mathrm{~min}$. The homogenate was centrifuged (HM-150IV, Hanil) at 17,030 $\mathrm{g}$ for $15 \mathrm{~min}$, and the supernatant was mixed with $750 \mathrm{~mL}$ acetonitrile. After storing at $4^{\circ} \mathrm{C}$ for $20 \mathrm{~min}$ and centrifuging (HM-150IV, Hanil, Korea) at $17,030 \mathrm{~g}$ for $10 \mathrm{~min}$, the supernatant was filtered through a $0.2-\mu \mathrm{m}$ PVDF syringe filter (Whatman) and injected into a HPLC column with a Waters 1525 pump and a Waters 717 plus autosampler (Millipore CoOperative, USA). An Atlantis HILIC silica column $(4.6 \times 150 \mathrm{~mm}, 3 \mu \mathrm{m}$, Waters) was used. A diode array detector (Waters 2487, Millipore Co-Operative, USA) was used at $214 \mathrm{~nm}$ for determining creatine, carnosine, and anserine, and at $236 \mathrm{~nm}$ for creatinine. The mobile A phase was $0.65 \mathrm{mM}$ ammonium acetate in water/acetonitrile $(25: 75, \mathrm{v} / \mathrm{v}, \mathrm{pH} 5.5)$ and the $\mathrm{B}$ phase was $4.55 \mathrm{mM}$ ammonium acetate in water/acetonitrile $(70: 30, \mathrm{v} / \mathrm{v}, \mathrm{pH}$ 5.5). The B phase was supplied at $1.2 \mathrm{~mL} / \mathrm{min}$ for $16 \mathrm{~min}$ with a linear gradient (0-100\%). Standards (creatine, anserine, carnosine, and creatinine) were obtained from Sigma (USA).

\section{Free amino acids}

The free amino acid composition was determined by using a modification of Hughes et al. (2002). Defatted meat samples ( $5 \mathrm{~g}$ ) were mixed with $20 \mathrm{~mL} 2 \%$ TCA solution and homogenized (T25b, Ika Works (Asia)) at $13,500 \mathrm{rpm}$ for $1 \mathrm{~min}$. The homogenate was centrifuged (HM-150IV, Hanil) at 17,030 $\mathrm{g}$ for $15 \mathrm{~min}$ and filtered through a $0.45-\mu \mathrm{m}$ membrane filter (Whatman). The filtrate was derivatized by the method of Waters AccQ-Tag ${ }^{\mathrm{TM}}$
(1993, Millipore Co-Operative, USA), and $5 \mathrm{~mL}$ was injected into a RP-HPLC column (AccQ-Tag ${ }^{\mathrm{TM}}$ column, 3.9 $\times 150 \mathrm{~mm}$, Waters). The column temperature was $37^{\circ} \mathrm{C}$, and a fluorescent detector (Waters ${ }^{\mathrm{TM}} 2475$, Millipore, USA) was used with $250 \mathrm{~nm}$ and $395 \mathrm{~nm}$ of excitation and emission wavelength respectively. Separation was conducted using buffers A (Waters AccQ-Tag eluent) and B $(60 \%, v / v$, acetonitrile). The accuracy and repeatability of this analysis was ensured by the inclusion of a control sample of known amino acid composition with the samples prior to hydrolysis.

\section{Fatty acids and cholesterol}

Lipids were extracted from samples according to the method of Folch et al. (1957). Meat samples (5 g) and 30 $\mathrm{mL}$ Folch solution (chloroform : methanol=2:1) were homogenized, and the homogenate was filtered through filter paper (No. 4, Whatman). The samples were thoroughly mixed after adding $0.88 \% \mathrm{KOH}$ solution. After phase separation, the upper layer was removed and the remaining organic layer was dried under nitrogen flow. The dried lipid was dissolved with an aliquot of hexane (at $100 \mathrm{mg}$ lipid/mL hexane) and used for fatty acid and cholesterol analysis.

One $\mathrm{mL} \mathrm{BF} \mathrm{BF}_{3}$-methanol (Sigma) was added to $100 \mathrm{~mL}$ lipid extract and the sample mixture was incubated in a $90^{\circ} \mathrm{C}$ for $1 \mathrm{~h}$. After cooling, $2 \mathrm{~mL}$ hexane and $5 \mathrm{~mL}$ distilled water were added, mixed thoroughly, and left overnight for phase separation. The top (hexane) layer containing methylated fatty acids was analyzed using a GC (HP 7890, Agilent Technologies, USA). A capillary column (HP-88, $60 \mathrm{~m} \times 0.25 \mathrm{~mm} \times 0.25 \mathrm{~mm}$, Agilent Technologies) was used. A ramped oven temperature condition $\left(180^{\circ} \mathrm{C}\right.$ for $1 \mathrm{~min}$, increased to $230^{\circ} \mathrm{C}$ by $2.5^{\circ} \mathrm{C} / \mathrm{min}$, then held at $230^{\circ} \mathrm{C}$ for $12 \mathrm{~min}$ ) was used. The temperature of both the inlet and detector was $280^{\circ} \mathrm{C}$. Helium was the carrier gas, maintained at a linear flow rate of $1 \mathrm{~mL} / \mathrm{min}$. The FID detector air, $\mathrm{H}_{2}$, and make-up gas $(\mathrm{He})$ flows were 350, 35, and $41 \mathrm{~mL} / \mathrm{min}$, respectively. Relative quantities were expressed as weight percent of total fatty acids identified via comparison of retention times to known standards (37 FAME mix, CLA mix, Sigma-Aldrich, USA).

For analysis of cholesterol, $10 \mathrm{~mL}$ of saponification reagent [33\% $\mathrm{KOH}(\mathrm{w} / \mathrm{v}) /$ ethanol, 6:94] was added to lipid extract. The sample was homogenized and then incubated for $1 \mathrm{~h}$ at $50^{\circ} \mathrm{C}$. After cooling, $5 \mathrm{~mL}$ of distilled water and $5 \mathrm{~mL}$ of hexane were added. The contents were mixed thoroughly and the hexane layer containing unsaponifiable matter was dried under nitrogen flow. To the dried 
sample, $200 \mathrm{~mL}$ of pyridine and $100 \mathrm{~mL}$ of Sylon BFT (99\% BSTFA + 1\% TMCS) were added and derivatized at $50^{\circ} \mathrm{C}$ for $1 \mathrm{~h}$. Analysis was performed with a HP 6890 GC equipped with an on-column capillary injector and FID detector. A capillary column (HP-5, $30 \mathrm{~m} \times 0.25 \mathrm{~mm} \times$ $0.25 \mathrm{~mm}$ ) was used. A ramped oven temperature was used $\left(180^{\circ} \mathrm{C}\right.$, increased to $260^{\circ} \mathrm{C}$ by $8^{\circ} \mathrm{C} / \mathrm{min}$, then increased to $280^{\circ} \mathrm{C}$ by $2^{\circ} \mathrm{C} / \mathrm{min}$ ). The quantity of cholesterol in each sample was calculated using an internal standard, 5acholestane.

\section{pH, water holding capacity, drip loss, and cooking loss}

The $\mathrm{pH}$ of samples was determined with a $\mathrm{pH}$ meter (SevenEasy, Mettler-Toledo, Korea). Meat samples (3 g) with $27 \mathrm{~mL}$ distilled water were mixed for $60 \mathrm{~s}$ with a homogenizer (T25b, Ika Works (Asia)) and filtered through a filter paper (No. 4, Whatman). The water holding capacity (WHC) was determined by the centrifugation method of Uttaro et al. (1993). Minced meat samples $(5 \mathrm{~g})$ were placed into centrifuge tubes with filter paper (No. 4, Whatman), and centrifuged (CR 20B2, Hitachi Koki Co., Ltd. Japan) for $10 \mathrm{~min}$ at $3,000 \mathrm{~g}$. WHC was calculated as the moisture remaining in meat samples in relation to the moisture content before centrifugation. Drip loss was measured as the percentage weight loss of a standardized-sized $(3 \times 3 \times 3 \mathrm{~cm})$ meat sample in a petri dish during the $2 \mathrm{~d}$ of storage at $4^{\circ} \mathrm{C}$. Cooking loss was measured as the percentage weight loss of a standardizedsized $(3 \times 3 \times 3 \mathrm{~cm})$ meat sample after cooking in an electric grill with double pans (Nova EMG-533, 1,400 W, Evergreen Enterprise, Korea) for $90 \mathrm{~s}$ until the internal temperature reached $72^{\circ} \mathrm{C}$.

\section{Instrumental color}

Color values were measured on the surface of meat samples with a colorimeter (CR-410, Minolta Co. Ltd., Japan). The colorimeter was calibrated against a white reference tile plate (CIE $L^{*}=89.2, a^{*}=0.921, b^{*}=0.783$ ), and the diameter of the aperture was $4 \mathrm{~cm}$. The color [CIE L* (lightness), $a^{*}$ (redness), and $b^{*}$ (yellowness)] values were obtained after $30 \mathrm{~min}$ blooming at room temperature. An average value from 5 random readings on each sample surface was used for statistical analysis.

\section{Sensory evaluation}

The sensory evaluation of total 246 LD muscles was performed through 31 sensory panels. For the sensory evaluation, meat samples $(2 \times 4 \times 1.5 \mathrm{~cm})$ were cooked in an electric grill with double pans (Nova EMG-533, 1,400 W, Evergreen Enterprise, Korea) to an internal temperature of $75^{\circ} \mathrm{C}$. The meat samples were placed into randomly coded white dishes and served with drinking water. Ten semitrained panelists recorded their preferences using 9-point hedonic scales ( 1 -profoundly dislike, $9=$ =profoundly like). The sensory parameters tested were color, odor, tenderness, juiciness, and overall acceptance.

\section{Statistical methods}

An analysis of variance was performed on all of the variables measured by the General Linear Model (GLM) procedure using SAS statistical package (SAS, 1999). The Duncan's multiple range test $(p<0.05)$ was used to determine differences among the treatment means. The mean values and the standard errors of the means (SEM) were reported. Pearson's correlation coefficients were calculated using the SAS statistical package (SAS, 1999).

\section{Results and Discussion}

\section{Yield index, carcass weight, ribeye area, and back fat thickness of Hanwoo steers}

The mean values of yield index and carcass traits (weight, ribeye area, and back fat thickness) among the different yield grades from Hanwoo steers are presented in Table 1. The average yield index of the carcasses was 69.4, 65.3, and 60.8 for yield grades A, B, and C, respectively. Carcass weight increased significantly $(p<0.05)$ with the decrease of yield grades from A to $\mathrm{C}$. The back fat thickness of yield grades $\mathrm{B}$ and $\mathrm{C}$ were 1.82 and 2.65 times higher than that of yield grade A, respectively ( $p<$ 0.05 ). It may be inferred that increased carcass weight and back fat thickness could be obtained by increasing the fattening period for Hanwoo steers, and would result in a decrease of yield grade from A to $\mathrm{C}$ from the present result. However, there was no significant difference in ribeye area among the different yield grades $(p=0.18)$. Lee $e t$ al. (2011) reported the yield index and carcass traits of Hanwoo steers $(\mathrm{n}=55,783)$ and showed that carcass yield indices of $69.89,65.93$, and 61.75 (similar to that of the present study) corresponded to carcass weights of 376 , 410 , and $431 \mathrm{~kg}$, respectively. These results are similar to those of the present study, in which yield indices of 69.4, 65.3, and 60.8 corresponded to carcass weights of 370 , 402 , and $432 \mathrm{~kg}$, respectively. In addition, back fat thickness was 2.05 (65.93) and 3.14 (61.75) times higher than that of carcass yield index at 69.89 , although back fat thickness measured by Lee et al. (2011) was lower than 
Table 1. Yield index and traits of carcass, and proximate composition and cholesterol content of Longissimus dorsi muscle from Hanwoo steers at different yield grades

\begin{tabular}{|c|c|c|c|c|}
\hline & \multicolumn{3}{|c|}{ Yield grade } & \multirow[b]{2}{*}{ SEM $^{1}$} \\
\hline & $\begin{array}{c}\mathrm{A} \\
(\mathrm{n}=77)\end{array}$ & $\begin{array}{c}\mathrm{B} \\
(\mathrm{n}=76)\end{array}$ & $\begin{array}{c}\mathrm{C} \\
(\mathrm{n}=93)\end{array}$ & \\
\hline Yield index & $69.4^{\mathrm{a}}$ & $65.3^{\mathrm{b}}$ & $60.8^{\mathrm{c}}$ & 0.19 \\
\hline Carcass weight (kg) & $370^{\mathrm{c}}$ & $402^{\mathrm{b}}$ & $432^{\mathrm{a}}$ & 4.7 \\
\hline Ribeye area $\left(\mathrm{cm}^{2}\right)$ & 87.5 & 89.8 & 90.0 & 1.04 \\
\hline Back fat thickness (mm) & $7.2^{\mathrm{c}}$ & $13.1^{\mathrm{b}}$ & $19.1^{\mathrm{a}}$ & 0.28 \\
\hline Moisture (\%) & $65.3^{\mathrm{a}}$ & $63.7^{\mathrm{b}}$ & $63.0^{\mathrm{b}}$ & 0.54 \\
\hline Crude protein $(\%)$ & 19.3 & 19.4 & 19.3 & 0.20 \\
\hline Crude fat (\%) & $13.5^{\mathrm{b}}$ & $15.4^{\mathrm{a}}$ & $16.2^{\mathrm{a}}$ & 0.54 \\
\hline Crude ash (\%) & 1.09 & 1.05 & 1.07 & 0.026 \\
\hline Cholesterol (mg/100 g) & $59.7^{\mathrm{b}}$ & $61.1^{\mathrm{ab}}$ & $61.6^{\mathrm{a}}$ & 0.64 \\
\hline
\end{tabular}

${ }^{1}$ Standard errors of mean $(n=246)$.

${ }^{\mathrm{a}-\mathrm{c}}$ Different letters within same row differ significantly $(p<0.05)$.

that of the present study. However, Lee et al. (2011) found a significant difference in ribeye area between yield indices of 69.89 and 61.75, while there were no significant differences in the ribeye area among different yield indices in the present study.

The correlation coefficient for yield grade and carcass traits is shown in Table 2. The yield grade of Hanwoo steer carcasses $(n=246)$ had a highly negative correlation with back fat thickness $(-0.89)$ and a negative correlation with carcass weight $(-0.52)$. This result agreed with that of the previous study. Lee et al. (2011) reported that the yield grade of Hanwoo steer carcasses $(n=55,783)$ was negatively correlated with back fat thickness (-0.85). In addition, Moon et al. (2003) found a partial $\mathrm{R}^{2}$ value of 0.66 in regression analysis between yield grade and back fat thickness of Hanwoo steer carcasses $(n=14,386)$ and reported that back fat thickness was the prime determinant of yield grade. Carcass weight had a positive correlation with ribeye area (0.61) and back fat thickness (0.51), and back fat thickness had a positive correlation with ribeye area (0.21). These results also agreed with the report by Lee et al. (2011), who found an increase in carcass weight and ribeye area when back fat thickness was increased.

The results obtained in the present study agree with results from previous studies, although our sample size was smaller than that of previous studies. Therefore, we sug- gest that the sample size from the present study could be sufficient to explain the differences in meat quality in accordance with yield grades of Hanwoo steer carcasses.

\section{Meat quality traits of LD muscle from 3 yield-grade groups of Hanwoo steers}

The proximate composition of LD muscle from the 3 yield-grade groups is shown in Table 1. The crude protein and ash contents of LD muscle were not significantly different among the 3 groups. The moisture content of LD muscle was higher in yield grade $\mathrm{A}$ than in yield grades $\mathrm{B}$ and $\mathrm{C}(p<0.05)$. In contrast, the crude fat content of LD muscle from yield grades $\mathrm{B}$ and $\mathrm{C}$ was higher than that from yield grade A $(p<0.05)$. Generally, there is a negative relationship between moisture content and crude fat content of meat. The moisture content of loin muscle from Hanwoo beef was low in muscles that included large amounts of crude fat (Kim and Lee, 2003). Pflanzer and de Felicio (2011) reported a correlation coefficient of -0.92 between moisture and fat contents in M. Longissimus thoracis muscle from cattle $(p<0.05)$. High crude fat content in LD is related to high back fat thickness. Bruns et al. (2004) and Orellana et al. (2009) found that intramuscular fat content of Longissimus muscle was positively linked to back fat thickness at the $10^{\text {th }}$ or $12^{\text {th }}$ ribs in cattle. In addition, Indurain et al. (2009) reported a correlation coefficient of 0.705 between intramuscular fat

Table 2. Correlation coefficient for among yield grade, carcass weight, ribeye area, and back fat thickness of carcass from Hanwoo steers

\begin{tabular}{|c|c|c|c|}
\hline & Yield grade & Carcass weight & Ribeye area \\
\hline Carcass weight (kg) & $-0.52 * * *$ & & \\
\hline Ribeye area $\left(\mathrm{cm}^{2}\right)$ & -0.11 & $0.61 * * *$ & \\
\hline Back fat thickness (mm) & $-0.89 * * *$ & $0.51 * * *$ & $0.21 * *$ \\
\hline
\end{tabular}

$* * p<0.01, * * * p<0.001$ 
content of Longissimus muscle and fat thickness at the $6^{\text {th }}$ rib $(p<0.001)$ in Spanish beef. The high crude fat content of LD muscle from yield grade $\mathrm{C}$ resulted in high cholesterol content of the muscle compared to that from yield grade A $(p<0.05)$. This result agreed with the findings of previous studies. Lee et al. (2010) found a higher cholesterol content in Hanwoo loin muscles when the muscles had higher crude fat content $(p<0.05)$. In addition, a positive relationship between intramuscular cholesterol and intramuscular lipid in M. Longissimus thoracis muscle from Wagyu and Angus steers was reported (Chung et al., 2006).

Nucleotide breakdown products are generated with degradation of adenosine triphosphate (ATP) in meat after slaughter (Yano et al., 1995). The progress of nucleotide breakdown is as follows: after slaughter, ATP degrades rapidly to adenosine monophosphate (AMP), which then undergoes enzymatic reaction by deaminase and results in accumulation of inosine 5-monophosphate (IMP). The IMP is hydrolyzed to inosine (HxR) by 5-nucleotidase, and the HxR breaks down to hypoxanthine $(\mathrm{Hx})$ by purine nucleotide phosphorylase (Surette et al., 1988). The AMP and HxR content of LD muscle from the 3 yield grades was not significantly different (Table 3 ). The IMP content of LD muscle from yield grade A was $118.3 \mathrm{mg} / 100 \mathrm{~g}$, which was higher than the $97.6 \mathrm{mg} / 100 \mathrm{~g}$ from yield grade $\mathrm{C}(p<0.05)$. In contrast, the $\mathrm{Hx}$ content of LD muscle from yield grade A was lower than that of yield grades B and $\mathrm{C}(p<0.05)$. The content of nucleotide breakdown products in beef changes with aging (Yano et al., 1995). Vani et al. (2006) reported that acidic $\mathrm{pH}$ and high temperatures increased the degradation rate of nucleotides in meat. In the present study, carcasses from yield grade $\mathrm{C}$ had high weight and back fat thickness. Both high carcass weight and back fat thickness can reduce the rate of temperature decline, and consequently result in an increased rate of $\mathrm{pH}$ decline, in cattle carcasses (Park et al., 2007). Therefore, the degradation rate of nucleotides may be fast in carcasses from yield grade $\mathrm{C}$ compared to carcasses from yield grade $\mathrm{A}$, although there were no significant $\mathrm{pH}$ differences in the LD muscle among the 3 yield grades. Further study is needed to improve the understanding of these dynamics. The lower IMP and higher Hx content of LD muscle from yield grade $\mathrm{C}$ could lead to decrease the sensorial quality of LD muscle when compared to LD muscle from yield grade A. Nucleotides are among the precursors to meat flavor (Kawai et al., 2002). IMP, in particular, has been known to generate the "umami" taste (described as savory), alone or when conjugated with monosodium glutamate for synergistic effects (Kawai et al., 2002; Koutsidis et al., 2008). Contrarily, Hx may contribute a bitter taste to meat by conjugating certain amino acids and peptides (Tikk et al., 2006).

Histidine dipeptides such as carnosine and anserine, and creatine are categorized as bioactive substances from animal sources (Schmid, 2009). Carnosine ( $\beta$-alanyl-L-histidine) and anserine ( $\beta$-alanyl- $N$-methyl-L-histidine, an $\mathrm{N}$ methylated derivative of carnosine) are distributed in vertebrate tissues, and have bioactive properties such as antiageing that are related to antioxidative activity and reducing activity of advanced glycosylation end-products (Bellia et al., 2011; Schmid, 2009). Creatine [N-(amonoiminomethyl)-N-methyl-glycine] is abundant in skeletal muscles (Purchas and Busboom, 2005). Its biological activity is to act as an energy supply to muscles (Wyss and Kaddurah-Daouk, 2000). Creatine is transported from the liver, in which it is primarily synthesized, to muscle and other organs, and then it undergoes phosphorylation. Creatine phosphate enables conversion of adenosine diphosphate (ADP) to ATP (Wyss and Kaddurah-Daouk, 2000). Liu (2011) reported that the contents of carnosine, anserine, creatine, and creatinine of Longissimus muscle from

Table 3. Nucleotide, dipeptides, creatine, and creatinine content (mg/100 g) of Longissimus dorsi muscle from Han- woo steers at different yield grades

\begin{tabular}{|c|c|c|c|c|}
\hline & \multicolumn{3}{|c|}{ Yield grade } & \multirow{2}{*}{$\mathrm{SEM}^{1}$} \\
\hline & A & $\mathrm{B}$ & $\mathrm{C}$ & \\
\hline Adenosine-5-phosphate (AMP) & 7.1 & 6.8 & 6.9 & 0.18 \\
\hline Inosine-5-phosphate (IMP) & $118.3^{\mathrm{a}}$ & $109.6^{\mathrm{ab}}$ & $97.6^{\mathrm{b}}$ & 5.48 \\
\hline Hypoxanthine $(\mathrm{Hx})$ & $25.1^{\mathrm{b}}$ & $27.6^{\mathrm{a}}$ & $28.8^{\mathrm{a}}$ & 0.84 \\
\hline Inosine (HxR) & 21.2 & 20.9 & 22.2 & 0.68 \\
\hline Carnosine & 682.9 & 724.2 & 714.6 & 16.92 \\
\hline Anserine & 127.3 & 111.9 & 117.2 & 6.05 \\
\hline Creatine & $1,504.8$ & $1,531.0$ & $1,495.0$ & 15.47 \\
\hline Creatinine & $16.3^{\mathrm{b}}$ & $18.9^{\mathrm{a}}$ & $20.8^{\mathrm{a}}$ & 0.87 \\
\hline
\end{tabular}

${ }^{1}$ Standard errors of mean $(n=246)$.

${ }^{a, b}$ Different letters within same row differ significantly $(p<0.05)$. 
Angus cattle was 372, 67, 526, and $21 \mathrm{mg} / 100 \mathrm{~g}$, respectively. The contents of carnosine, creatine, and creatinine of semi-tendinous muscle from prime cattle in New Zealand were 452,401 , and $5.8 \mathrm{mg} / 100 \mathrm{~g}$, respectively (Purchas et al., 2004). In the present study, there were no significant differences in the contents of carnosine, anserine, and creatine in the LD muscles among the 3 yield grades (Table 3). The average contents of carnosine, anserine, and creatine in LD muscles from yield grades A, B, and C were 707,119 , and $1510 \mathrm{mg} / 100 \mathrm{~g}$, respectively. This result showed that the contents of these compounds in LD muscles of Hanwoo cattle were high compared to those of meat from Angus in New Zealand. Therefore, Hanwoo beef could be expected to have high nutritional quality compared to other breeds of beef. The content of creatinine in $\mathrm{LD}$ muscle from yield grade $\mathrm{C}$ was higher than that from yield grade A $(p<0.05)$. Creatinine is a breakdown product of creatine, and has been discovered in the skeletal muscle (Wyss and Kaddurah-Daouk, 2000). Liu (2011) reported that creatinine contents of Longissimus muscle from Angus cattle had a positive correlation with carcass weight and back fat thickness. The breakdown of creatine to creatinine was shown to be positively affected by temperature (Purchas et al., 2004). Therefore, the significant difference in the creatinine content of LD muscle between yield grades $\mathrm{A}$ and $\mathrm{C}$ may be affected by the rate of temperature decline of the carcass, as described above.

The aspartic acid and histidine contents of the LD muscle from yield grade A were significantly higher than those from yield grade C (Table 4); the contents of the other free amino acids in LD muscle did not differ among the yield grades. Free amino acids are meat flavor precursor, alone or when conjugated with other molecules such as sugars and nucleotides (Koutsidis et al., 2008). Wong et al. (2008) reported that aspartic acid produced a fruity, pleasant, and sweet aroma by the Maillard reaction with glucose after heating, but that histidine did not produce any aroma. A previous study reported that an increase in the slaughter age of Wagyu cattle $(15,25$, and $35 \mathrm{mo})$ led to accumulation of fat in the muscle and to low muscle growth, which resulted in decreased total amounts of free amino acids, and differences in some amino acid contents in the LD muscle (Watanabe et al., 2004). In that study, aspartic acid contents decreased with increasing slaughter age (Watanabe et al., 2004). When the carcass weights were considered, it can be expected that the slaughter age of Hanwoo steers of yield grade $\mathrm{C}$ may be older than that of yield grade A. However, the total amount of free amino acids in LD muscle did not differ among the 3 yield grades (data not shown).

The fatty acid composition of beef fat is primarily affected by regimen and genotype (Alfaia et al., 2006). In addition, the duration of fattening, age, carcass weight, and degree of fat deposition influence the fatty acid composition of beef fat (Iwamoto et al., 2009). In the present study, the effect of genotype and feed on fatty acid composition of intramuscular fat from LD muscle was restricted because the carcasses used in this study were de-

Table 4. Free amino acid content (mg/100 g) of longissimus dorsi muscle from Hanwoo steers at different yield grades

\begin{tabular}{|c|c|c|c|c|}
\hline \multirow{2}{*}{ Free amino acid } & \multicolumn{3}{|c|}{ Yield grade } & \multirow{2}{*}{ SEM $^{1}$} \\
\hline & $\mathrm{A}$ & $\mathrm{B}$ & $\mathrm{C}$ & \\
\hline Ala & 47.0 & 50.2 & 47.1 & 1.69 \\
\hline Arg & 292.2 & 311.3 & 291.9 & 9.11 \\
\hline Asp & $2.4^{\mathrm{a}}$ & $2.5^{\mathrm{a}}$ & $1.8^{\mathrm{b}}$ & 0.17 \\
\hline Cys & 5.4 & 6.1 & 6.0 & 0.40 \\
\hline Glu & 11.4 & 12.2 & 12.9 & 0.81 \\
\hline Gly & 11.4 & 12.4 & 11.2 & 0.51 \\
\hline His & $115.2^{\mathrm{a}}$ & $104.6^{\mathrm{ab}}$ & $97.3^{\mathrm{b}}$ & 4.22 \\
\hline ile & 5.3 & 6.2 & 5.9 & 0.39 \\
\hline Leu & 9.4 & 10.9 & 10.2 & 0.64 \\
\hline Lys & 11.5 & 13.1 & 12.4 & 0.62 \\
\hline Met & 4.2 & 4.9 & 4.6 & 0.33 \\
\hline Phe & 5.7 & 6.7 & 6.3 & 0.41 \\
\hline Pro & 5.6 & 5.9 & 5.5 & 0.23 \\
\hline Ser & 13.4 & 14.2 & 13.1 & 0.72 \\
\hline Thr & 35.7 & 36.3 & 34.4 & 1.66 \\
\hline Tyr & 6.4 & 7.3 & 6.7 & 0.38 \\
\hline Val & 7.9 & 8.9 & 8.4 & 0.54 \\
\hline
\end{tabular}

${ }^{1}$ Standard errors of mean $(n=246)$.

${ }^{\mathrm{a}, \mathrm{b}}$ Different letters within same row differ significantly $(p<0.05)$. 
rived from Hanwoo steers grown with commercial feed. The predominant fatty acids of intramuscular fat in the LD muscle from the 3 yield grades were palmitic (C16:0) and stearic (C18:0) acids as saturated fatty acids (SFA), oleic acid (C18:0) as a monounsaturated fatty acid (MUFA), and linoleic acid (C18:2) as a polyunsaturated fatty acid (PUFA), which agree with a report by Dashdorj et al. (2012). Significant differences $(p<0.05)$ in the contents of some fatty acids in intramuscular fat from LD muscle were confirmed among the 3 yield grades (Table 5). The compositions of lauric (C12:0), myristic (C14:0), penta- decyclic (C15:0), and margaric acids (C17:0) were higher in yield grade $\mathrm{A}$ than in yield grades $\mathrm{B}$ and $\mathrm{C}(p<0.05)$, and the composition of stearic acid (C18:0) from yield grade A was higher than that from yield grade $\mathrm{C}(p<$ 0.05 ). These results showed that the intramuscular fat of LD muscle from yield grade A had significantly higher SFA composition than intramuscular fat from yield grades $\mathrm{B}$ and $\mathrm{C}(p<0.05)$. In contrast, the MUFA composition of intramuscular fat was high in yield grades $\mathrm{B}$ and $\mathrm{C}$ compared to yield grade $\mathrm{A}$ as a result of high contents of oleic $(\mathrm{C} 18: 1)$ and eicosenoic $(\mathrm{C} 20: 1)$ acids in yield grades B

Table 5. Fatty acid composition (\%) of intramuscular fat from Longissimus dorsi muscle from Hanwoo steers at different yield grades and the ratio of CLA/SFA+cholesterol

\begin{tabular}{|c|c|c|c|c|}
\hline & \multicolumn{3}{|c|}{ Yield grade } & \multirow{2}{*}{ SEM $^{1}$} \\
\hline & $\mathrm{A}$ & $\mathrm{B}$ & $\mathrm{C}$ & \\
\hline C10:0 & 0.04 & 0.04 & 0.04 & 0.001 \\
\hline C12:0 & $0.10^{\mathrm{a}}$ & $0.08^{\mathrm{b}}$ & $0.08^{\mathrm{b}}$ & 0.003 \\
\hline C14:0 & $2.86^{\mathrm{a}}$ & $2.68^{\mathrm{b}}$ & $2.62^{\mathrm{b}}$ & 0.063 \\
\hline C14:1 & 0.84 & 0.80 & 0.82 & 0.032 \\
\hline C15:0 & $0.27^{\mathrm{a}}$ & $0.23^{\mathrm{b}}$ & $0.23^{\mathrm{b}}$ & 0.011 \\
\hline $\mathrm{C} 16: 0$ & 24.94 & 24.49 & 24.60 & 0.221 \\
\hline C16:1 & 4.04 & 4.15 & 3.99 & 0.143 \\
\hline $\mathrm{C} 17: 0$ & $0.68^{\mathrm{a}}$ & $0.62^{\mathrm{b}}$ & $0.61^{\mathrm{b}}$ & 0.018 \\
\hline $\mathrm{C} 17: 1$ & 0.74 & 0.70 & 0.70 & 0.020 \\
\hline C18:0 & $11.66^{\mathrm{a}}$ & $11.15^{\mathrm{ab}}$ & $10.93^{\mathrm{b}}$ & 0.238 \\
\hline C18:1 & $46.00^{\mathrm{b}}$ & $47.11^{\mathrm{a}}$ & $47.92^{\mathrm{a}}$ & 0.331 \\
\hline $\mathrm{C} 18: 1_{11 \mathrm{t}}$ & 2.14 & 2.34 & 2.31 & 0.089 \\
\hline C18:2 & 3.39 & 3.28 & 3.01 & 0.130 \\
\hline $\mathrm{C} 18: 2_{9 \mathrm{c} 11 \mathrm{t}}^{2}$ & 0.36 & 0.38 & 0.36 & 0.017 \\
\hline $\mathrm{C} 18: 2_{10 t 12 \mathrm{c}^{2}}$ & 0.02 & 0.02 & 0.03 & 0.003 \\
\hline C18:3 & 0.12 & 0.11 & 0.11 & 0.008 \\
\hline C20:0 & 0.05 & 0.05 & 0.05 & 0.002 \\
\hline C20:1 & $0.31^{\mathrm{b}}$ & $0.37^{\mathrm{a}}$ & $0.35^{\mathrm{a}}$ & 0.012 \\
\hline C20:2 & $0.21^{\mathrm{a}}$ & $0.15^{\mathrm{ab}}$ & $0.12^{\mathrm{b}}$ & 0.031 \\
\hline C20:3 & 0.34 & 0.35 & 0.32 & 0.015 \\
\hline C20:4 & 0.69 & 0.70 & 0.63 & 0.042 \\
\hline C24:1 & 0.18 & 0.19 & 0.17 & 0.009 \\
\hline $\mathrm{SFA}^{3}$ & $40.61^{\mathrm{a}}$ & $39.35^{\mathrm{b}}$ & $39.16^{\mathrm{b}}$ & 0.358 \\
\hline MUFA $^{4}$ & $54.25^{\mathrm{b}}$ & $55.65^{\mathrm{a}}$ & $56.27^{\mathrm{a}}$ & 0.356 \\
\hline PUFA $^{5}$ & $5.13^{\mathrm{a}}$ & $5.00^{\mathrm{ab}}$ & $4.57^{\mathrm{b}}$ & 0.175 \\
\hline $\mathrm{UFA}^{6}$ & $59.39^{\mathrm{b}}$ & $60.65^{\mathrm{a}}$ & $60.84^{\mathrm{a}}$ & 0.358 \\
\hline PUFA/SFA & 0.13 & 0.13 & 0.12 & 0.005 \\
\hline$n-6 / n-3^{7}$ & 9.59 & 9.09 & 8.99 & 0.249 \\
\hline $\begin{array}{c}\text { CLA/ } \\
\text { SFA+cholesterol }\end{array}$ & 0.009 & 0.010 & 0.010 & 0.0004 \\
\hline
\end{tabular}

${ }^{1}$ Standard errors of mean $(n=246)$.

${ }^{\mathrm{a}, \mathrm{b}}$ Different letters within same row differ significantly $(p<0.05)$.

${ }^{2} \mathrm{CLA}$, conjugated linoleic acid

${ }^{3}$ SFA, saturated fatty acid (sum of C10:0, C12:0, C14:0, C15:0, C17:0, C18:0, and C20:0)

${ }^{4}$ MUFA, monounsaturated fatty acid (sum of C14:1, C16:1, C17:1, C18:1, C18:1 ${ }_{11}, \mathrm{C} 20: 1$, and C24:1)

${ }^{5}$ PUFA, polyunsaturated fatty acid (sum of C18:2, C18:2 ${ }_{9 \mathrm{c} 11 \mathrm{t}}, \mathrm{C} 18: 2_{10 \mathrm{t} 12 \mathrm{c}}, \mathrm{C} 18: 3, \mathrm{C} 20: 2, \mathrm{C} 20: 3$, and $\mathrm{C} 20: 4$ )

${ }^{6}$ UFA, unsaturated fatty acid (sum of MUFA and PUFA)

${ }^{7} \mathrm{n}-6 / \mathrm{n}-3$, (sum of $\mathrm{C} 18: 2, \mathrm{C} 20: 2$, and $\left.\mathrm{C} 20: 4\right) /($ sum of $\mathrm{C} 18: 3$ and $\mathrm{C} 20: 3$ )

${ }^{8} \mathrm{CLA} / \mathrm{SFA}+$ cholesterol, sum of C18:2 ${ }_{9 \mathrm{c} 1 \mathrm{tt}}$ and $\mathrm{C} 18: 2_{10 \mathrm{t} 12 \mathrm{c}}(\mathrm{mg} / 100 \mathrm{~g}$ of meat) / SFA+cholesterol (mg /100 g of meat) 
and $\mathrm{C}(p<0.05)$. This result partially agreed with that of a study by Xie et al. (1996), who reported that oleic acid and stearic acid had positive and negative correlations with fat thickness, respectively. In addition, an increase in the fattening period resulted in increased activity of stearoyl-CoA desaturase, which converted SFAs to their corresponding MUFAs (Chung et al., 2007; Iwamoto et al., 2009). In the present study, the carcasses from yield grades $\mathrm{B}$ and $\mathrm{C}$ had greater fat thickness compared to that from yield grade $\mathrm{A}$, and this result could have been caused by prolongation of the fattening period. The content of eicosadienoic acid (C20:2) was higher in the intramuscular fat from yield grade A compared to that from yield grade C. However, other PUFAs in intramuscular fat did not differ significantly among the 3 yield grades. These results led to the significantly higher PUFA composition in intramuscular fat from yield grade A compared to that from yield grade $\mathrm{C}(p<0.05)$. The results from this study are similar to those reported by Sami et al. (2004), who found that increasing fatness in cattle was associated with an increased proportion of MUFAs and decreased proportion of PUFAs. The fatty acid proportions of intramuscular fat (low SFAs and high UFAs mainly because of high oleic acid) in LD muscle from yield grades $B$ and $C$ could affect the sensory quality of the meat in these grades. A previous study reported that SFAs and UFAs had negative and positive association with sensory panel scores respectively (Westerling and Hedrick, 1979). In addition, Sami et al. (2004) reported that an increase in the proportion of oleic acid affected the tenderness and flavor intensity of beef.

The PUFA/SFA and n-6/n-3 ratios are generally used to evaluate the nutritional value of fat (Orellana et al., 2009). In the present study, there was no significant difference in either of these ratios in intramuscular fat from the 3 yield grades. Beef fat contains conjugated linoleic acid (CLA), which consists of positional isomers of linoleic acid (C18:2 ${ }_{9-11 t}$ and C18:2 ${ }_{10 t-12 c}$ ) and is well known as a bioactive substance with anticarcinogenic effects (Schmid. 2009).
However, beef fat also contains SFAs and cholesterol, which are thought to affect the development of colon cancer (Eynard and Lopez, 2003). Therefore, Eynard and Lopez (2003) suggested the ratio of CLA/(SFA+cholesterol) in beef to evaluate the nutritional value of the meat in relation to colon cancer. In the present study, the ratio of CLA/(SFA+cholesterol) in LD muscle from yield grades $\mathrm{A}, \mathrm{B}$, and $\mathrm{C}$ was $0.009,0.010$, and 0.010 , respectively, and there were no significant differences in these values.

The surface colors expressed as CIE L*, CIE a*, and CIE $b^{*}$ values of LD muscle were not significantly different among the yield grades (data not shown). Meat color can be affected by various factors, including $\mathrm{pH}$ and water holding capacity (Boles et al., 2005; Swatland, 2008). In the present study, there was no significant difference in $\mathrm{pH}$ (data not shown). Water holding capacity, drip loss, and cooking loss of LD muscle did not differ among the 3 yield grades (data not shown). The water holding capacity of meat is mainly affected by the ultimate $\mathrm{pH}$ of the meat, and influences drip loss and cooking loss (HuffLonergan and Lonergan, 2005). Therefore, the lack of significant differences in water holding capacity, drip loss, and cooking loss of LD muscle among the 3 yield grades was regarded as an effect of similar $\mathrm{pH}$ of the LD muscle in the different grades.

In the sensory analysis of LD muscle from the 3 yield grades, the LD muscle from yield grade $\mathrm{C}$ got high scores for texture and juiciness compared to yield grade A (Table 6). The sensory parameters, such as color and odor, did not differ significantly among the yield grades. High intramuscular fat content in beef was reported to lead to high water holding capacity and low cooking loss, which make beef more juicy and tender (Jeremiah et al., 2003). Dashdorj et al. (2012) reported that increasing the feeding duration of Hanwoo steers from 26 to 32 months resulted in increased intramuscular fat content and decreased cooking loss of Longissimus muscle, which led to increased juiciness, but they did not find a change in the tenderness of the Longissimus muscle. Park et al. (2000) also re-

Table 6. Sensory analysis of longissimus dorsi muscle from Hanwoo steers at different yield grades

\begin{tabular}{ccccc}
\hline \hline & & Yield grade & C & \multirow{2}{*}{ SEM $^{1}$} \\
\cline { 2 - 4 } & $\mathrm{A}$ & $\mathrm{B}$ & 5.27 & 0.098 \\
Color & 5.22 & 5.11 & 5.09 & 0.261 \\
Odor & 5.28 & 4.94 & $5.16^{\mathrm{a}}$ & 0.153 \\
Texture & $4.71^{\mathrm{b}}$ & $5.09^{\mathrm{ab}}$ & $5.27^{\mathrm{a}}$ & 0.147 \\
Juiciness & $4.83^{\mathrm{b}}$ & $5.21^{\mathrm{ab}}$ & 5.09 & 0.147 \\
Overall acceptance & 4.69 & 5.07 & & \\
\hline
\end{tabular}

${ }^{1}$ Standard errors of mean $(n=246)$.

${ }^{a, b}$ Different letters within same row differ significantly $(p<0.05)$. 
ported increased scores for juiciness and tenderness with a gradual increase in the intramuscular fat content of LD muscle from Hanwoo cattle. However, they did not find a significant increase in the water holding capacity or cooking loss for intramuscular fat contents of $2 \%$ to $12 \%$. These results were similar to those of the present study. We found no significant difference in water holding capacity or cooking loss of LD muscle among the 3 yield grades despite significant differences in crude fat content of the LD muscle. Nevertheless, the texture and juiciness of LD muscle was improved in yield grade $\mathrm{C}$ compared to yield grade $\mathrm{A}$. The LD muscle from yield grade $\mathrm{A}$ had desirable sensory traits such as high IMP, low Hx, and high aspartic acid compared with those of LD muscle from yield grade $\mathrm{C}$, and LD muscle from yield grades $\mathrm{B}$ and $\mathrm{C}$ had a desirable fatty acid composition for sensory quality. However, there was no significant difference in overall acceptance for LD muscle among the 3 yield grades.

\section{Conclusions}

Differences in the meat quality traits were found among 3 yield grades of Hanwoo cattle carcasses. The crude fat and cholesterol contents of LD muscle from Hanwoo beef increased as yield grade declined from A to $\mathrm{C}$. This could be considered as a decline in nutritional quality in the aspect of negative perception of consumer against red meats. In addition, the decline in yield grade from $\mathrm{A}$ to $\mathrm{C}$ resulted in decreasing the meat flavor factors such as IMP and aspartic acid. Therefore, we suggest that the changes of substances related with health and flavor can be considered in order to obtain better quality Hanwoo beef.

\section{Acknowledgements}

This research was supported by the Technology Development Program for Agriculture and Forestry (Project No. 311016-3), Ministry of Agriculture, Forestry, and Fisheries, Republic of Korea and partially supported by Cooperative Research Program for Agriculture Science and Technology Development (Project No. PJ90701104), Rural Development Administration, Republic of Korea.

\section{References}

1. AOAC. (1995) Official methods of analysis ( $16^{\text {th }}$ revised ed.), Washington, DC: Association of Official Analysis Chemists.

2. Alfaia, C. M. M., Ribeiro, V. S. S., Lourenco, M. R. A., Quaresma, M. A. G., Martins, S. I. V., Portugal, A., Fontes, C. M.
G. A., Bessa, R. J. B., Castro, M. L. F., and Prates, J. A. M. (2006) Fatty acid composition, conjugated linoleic acid isomers and cholesterol in beef from crossbred bullocks intensively produced and from Alentejana purebred bullocks reared according to Carnalentejana-PDO specifications. Meat Sci. 72, 425-436.

3. Bellia, F., Vecchio, G., Cuzzocrea, S., Calabrese, V., and Rizzarelli, E. (2011) Neuroprotective features of carnosine in oxidative driven diseases. Mol. Aspects Med. 32, 258-266.

4. Boles, J. A., Bowman, J. G. P., Boss, D. L., and Surber, L. M. M. (2005) Meat color stability affected by barley variety fed in finishing diet to beef steers. Meat Sci. 70, 633-638.

5. Bruns, K. W., Pritchard, R. H., and Boggs, D. L. (2004) The relationships among body weight, body composition, and intramuscular fat content in steers. J Anim Sci. 82, 1315-1322.

6. Chung, K. Y., Lunt, D. K., Choi, C. B., Chae, S. H., Rhoades, R. D., Adams, T. H., Booren, B., and Smith, S. B. (2006) Lipid characteristics of subcutaneous adipose tissue and M-longissimus thoracis of Angus and Wagyu steers fed to US and Japanese endpoints. Meat Sci. 73, 432-441.

7. Chung, K. Y., Lunt, D. K., Kawachi, H., Yano, H., and Smith, S. B. (2007) Lipogenesis and stearoyl-CoA desaturase gene expression and enzyme activity in adipose tissue of short- and long-fed Angus and Wagyu steers fed corn- or hay-based diets. J. Anim. Sci. 85, 380-387.

8. Dashdorj, D., Oliveros, M. C. R., and Hwang, I. (2012) Meat quality traits of Longissimus muscle of Hanwoo steers as a function of interaction between slaughter endpoint and chiller ageing. Korean J. Food Sci. An. 32, 414-427.

9. Eynard, A. and Lopez, C. B. (2003) Conjugated linoleic acid (CLA) versus saturated fats/cholesterol: Their proportion in fatty and lean meats may affect the risk of developing colon cancer. Lipids Health Dis. 2, 1-5.

10. Folch, J., Lees, M., and Sloane-Stanley, G. H. (1957) A simple method for the isolation and purification of total lipids from animal tissues. J. Biol. Chem. 226, 497-507.

11. Harper, G. S. and Pethick, D. W. (2004) How might marbling begin? Aust. J. Exp. Agr. 44, 653-662.

12. Huff-Lonergan, E. and Lonergan, S. M. (2005) Mechanisms of water-holding capacity of meat: The role of postmortem biochemical and structural changes. Meat Sci. 71, 194-204.

13. Hughes, M. C., Kerry, J. P., Arendt, E. K., Kenneally, P. M., McSweeney, P. L. H., and O'Neill, E. E. (2002) Characterization of proteolysis during the ripening of semi-dry fermented sausages. Meat Sci. 62, 205-216.

14. Indurain, G., Carr, T. R., Goni, M. V., Insausti, K., and Beriain, M. J. (2009) The relationship of carcass measurements to carcass composition and intramuscular fat in Spanish beef. Meat Sci. 82, 155-161.

15. Iwamoto, E., Oka, A., and Iwaki, F. (2009) Effects of the fattening period on the fatty acid composition of fat deposits and free amino acid and inosinic acid contents of the longissimus muscle in carcasses of Japanese Black steers. Anim. Sci. J. 80, 411-417.

16. Jeremiah, L. E., Dugan, M. E. R., Aalhus, J. L., and Gibson, L. L. (2003) Assessment of the relationship between chemical 
components and palatability of major beef muscles and muscle groups. Meat Sci. 65, 1013-1019.

17. Jo, C., Cho, S. H., Chang, J., and Nam, K. C. (2012) Keys to production and processing of Hanwoo beef: A perspective of tradition and science. Animal Frontiers 2, 32-38.

18. Kawai, M., Okiyama, A., and Ueda, Y. (2002) Taste enhancements between various amino acids and IMP. Chem. Senses 27, 739-745.

19. Kim, C. J. and Lee, E. S. (2003) Effects of quality grade on the chemical, physical and sensory characteristics of Hanwoo (Korean native cattle) beef. Meat Sci. 63, 397-405.

20. Koutsidis, G., Elmore, J. S., Oruna-Concha, M. J., Campo, M. M., Wood, J. D., and Mottram, D. S. (2008) Water-soluble precursors of beef flavour. Part II: Effect of post-mortem conditioning. Meat Sci. 79, 270-277.

21. Lee, J. M., Choe, J. H., Park, H. K., Kim, Y. H., Park, B. Y., Kim, K. T., Koh, K. C., Seo, S. C., and Hwang, K. S. (2011) Effect of backfat thickness on the carcass grade factors and carcass price in Hanwoo cows and steers. Korean J. Food Sci. An. 31, 280-289.

22. Lee, Y. J., Kim, C. J., Park, B. Y., Seong, P. N., Kim, J. H., Kang, G. H., Kim, D. H., and Cho, S. H. (2010) Chemical composition, cholesterol, trans-fatty acids contents, $\mathrm{pH}$, meat color, water holding capacity and cooking loss of Hanwoo beef (Korean native cattle) quality grade. Korean J. Food Sci. An. 30, 997-1006.

23. Liu, Q. (2011) Concentration of creatine, creatinine, carnosine, and anserine in bovine longissimus muscle and their correlations with carcass and palatability traits. Master, thesis, Iowa State Univ., Iowa, USA.

24. Moon, S. S., Hwang, I. H., Jin, S. K., Lee, J. G., Joo, S. T., and Park, G. B. (2003) Carcass traits determining quality and yield grades of Hanwoo steers. Asian-Aust. J. Anim. Sci. 16, 10491054.

25. Mora, L., Sentandreu, M. A., and Toldra, F. (2007) Hydrophilic chromatographic determination of carnosine, anserine, balenine, creatine, and creatinine. J. Agr. Food Chem. 55, 46644669.

26. National Livestock Cooperative Federation. (1998) Korean carcass grading standard. Seoul: National Livestock Cooperative Federation.

27. Okumura, T., Saito, K., Sakuma, H., Nade, T., Nakayama, S., Fujita, K., and Kawamura, T. (2007) Intramuscular fat deposition in principal muscles from twenty-four to thirty months of age using identical twins of Japanese Black steers. J. Anim. Sci. 85, 1902-1907.

28. Orellana, C., Pena, F., Garcia, A., Perea, J., Martos, J., Domenech, V., and Acero, R. (2009) Carcass characteristics, fatty acid composition, and meat quality of Criollo Argentino and Braford steers raised on forage in a semi-tropical region of Argentina. Meat Sci. 81, 57-64.

29. Park, B. Y., Cho, S. H., Yoo, Y. M., Kim, J. H., Lee, J. M., Jung, S. K., and Kim, Y. K. (2000) Effect of intramuscular fat contents on the physicochemical properties of beef longissimus dorsi from Hanwoo. J. Anim. Sci. Technol. 42, 189-194.

30. Park, B. Y., Lee, J. M., and Hwang, I. H. (2007) Effect of post- mortem metabolic rate on meat color. Asian-Aust. J. Anim. Sci. 20, 598-604.

31. Pflanzer, S. B. and de Felicio, P. E. (2011) Moisture and fat content, marbling level and color of boneless rib cut from Nellore steers varying in maturity and fatness. Meat Sci. 87, 711.

32. Polkinghorne, R. J. and Thompson, J. M. (2010) Meat standards and grading A world view. Meat Sci. 86, 227-235.

33. Purchas, R. W. and Busboom, J. (2005) The effect of production system and age on levels of iron, taurine, carnosine, coenzyme Q(10), and creatine in beef muscles and liver. Meat Sci. 70, 589-596.

34. Purchas, R. W., Rutherfurd, S. M., Pearce, P. D., Vather, R., and Wilkinson, B. H. P. (2004) Concentrations in beef and lamb of taurine, carnosine, coenzyme $\mathrm{Q}_{10}$ and creatine. Meat Sci. 66, 629-637.

35. Sami, A. S., Augustini, C., and Schwarz, F. J. (2004) Effect of feeding intensity and time on feed on intramuscular fatty acid composition of Simmental bulls. J. Anim. Physiol. Anim. Nutr. 88, 179-187.

36. SAS. (1999) SAS/STAT Software for PC. Release 6.11, SAS Institute, Carg, NC, USA.

37. Schmid, A. (2009) Bioactive substances in meat and meat products. Fleischwirtschaft 89, 83-90.

38. Surette, M. E., Gill, T. A., and Leblanc, P. J. (1988) Biochemical basis of postmortem nucleotide catabolism in cod (Gadus-Morhua) and its relationship to spoilage. J. Agr. Food Chem. 36, 19-22.

39. Swatland, H. J. (2008) How pH causes paleness or darkness in chicken breast meat. Meat Sci. 80, 396-400.

40. Tikk, M., Tikk, K., Torngren, M. A., Meinert, L., Aaslyng, M. D., Karlsson, A. H., and Andersen, H. J. (2006) Development of inosine monophosphate and its degradation products during aging of pork of different qualities in relation to basic taste and retronasal flavor perception of the meat. J. Agr. Food Chem. 54, 7769-7777.

41. Uttaro, B. E., Ball, R. O., Dick, P., Rae, W., Vessie, G., and Jeremiah, L. E. (1993) Effect of ractopamine and sex on growth, carcass characteristics, processing yield, and meat quality characteristics of crossbred swine. J. Anim. Sci. 71, 2439-2449.

42. Vani, N. D., Modi, V. K., Kavitha, S., Sachindra, N. M., and Mahendrakar, N. S. (2006) Degradation of inosine-5'-monophosphate (IMP) in aqueous and in layering chicken muscle fibre systems: Effect of $\mathrm{pH}$ and temperature. $L W T$ - Food Sci. Technol. 39, 627-632.

43. van Koevering, M. T., Gill, D. R., Owens, F. N., Dolezal, H. G., and Strasia, C. A. (1995) Effect of time on feed on performance of feedlot steers, carcass characteristics, and tenderness and composition of longissimus muscles. J. Anim. Sci. 73, 2128.

44. Watanabe, A., Ueda, Y., and Higuchi, M. (2004) Effects of slaugher age on the levels of free amino acids and dipeptides in fattening cattle. Anim. Sci. J. 75, 361-367.

45. Westerling, D. B. and Hedrick, H. B. (1979) Fatty acid composition of bovine lipids as influenced by diet, sex and anatomical location and relationship to sensory characteristics. J. Anim. 
Sci. 48, 1343-1348.

46. Wong, K. H., Aziz, S. A., and Mohamed, S. (2008) Sensory aroma from Maillard reaction of individual and combinations of amino acids with glucose in acidic conditions. Int. J. Food Sci. Technol. 43, 1512-1519.

47. Wyss, M. and Kaddurah-Daouk, R. (2000) Creatine and creatinine metabolism. Physiol. Rev. 80, 1107-1213.

48. Xie, Y. R., Busboom, J. R., Gaskins, C. T., Johnson, K. A., Reeves, J. J., Wright, R. W., and Cronrath, J. D. (1996) Effects of breed and sire on carcass characteristics and fatty acid profiles of crossbred Wagyu and Angus steers. Meat Sci. 43, 167177.

49. Yano, Y., Kataho, N., Watanabe, M., Nakamura, T., and Asano, Y. (1995) Evaluation of beef aging by determination of hypoxanthine and xanthine contents-Application of a xanthine sensor. Food Chem. 52, 439-445.

$\overline{\text { (Received 2013.2.24/Revised 2013.4.16/Accepted 2013.4.17) }}$ 